\title{
CORRESPONDENCE
}

Is bran useful in diverticular disease? Sir Austin Bradford Hill, PHD, FRS; Sir Francis Avery Jones, FRCP...........4 46

Misplaced confidence in nebulised bronchodilators in severe asthmatic attacks

I Gregg, frCGP. . . . . . . . . . . 46

Bronchial hyperreactivity after inhalation of distilled water and saline

R A Lewis, MRCP, and Anne E Tattersfield, FRCP .................. 47

The secret technical defence: a case for changing the law

R A Goodbody, FRCPATH, and J J Smyth, QC; D E B Powell, mRCPath; G V Jaffé, MB; J E Horrocks, FRCPATH............47

Day hospital care by general practitioners W B Wright, FRCP............4 48

Primary health care in residential homes for the elderly

Ann P Bowling, PHD............ 48

Blood pressure reduction in the elderly

C W I Owens, MRCP, and T E Sensky, MB;
J R Coope, $M B$, and D G Beevers, $M D$; Mary R Bliss, MRCP; C P Petch, FRCP; J S Milne, FRCSED . . . . . . . . . . . . . . 49

Hyperglycaemic effect of nifedipine

R H Greenwood, MRCP............. 50

Dental health in patients susceptible to

infective endocarditis

Celia M Oakley, FRCP, and J H Darrell, MRCPATH ................ 50

Alcohol and alcoholism

K A Harden, MRCGP............. 51

ABC of alcohol

D B Jack, PHD; B M Wright, $M B$; R C

Peveler, DPHIL; Jennifer J Waterton, MSC 5

Rectal examination and acid phosphatase

A S Daar, FRCSED .............. 52

Hepatitis $B$ infection in

glomerulonephritis

J S O'Neill, MB .................. 52

Spirochaetosis: a remediable cause of

diarrhoea and rectal bleeding?

D S Tompkins, $M B$, and others......... 52

Facial burns due to fan heater

J M Morfitt, MFCMI............ 52
The handicapped child

Helene F Bell, BA................ 53

Confidentiality and informed consent

D H Howe, frcs.............. 53

Audit in general practice

R K Brown, MRCGP and others. . . . . . . . 53

Postgraduate training in general practice

Captain T O Jefferson, DMs.......... 54

Part-time medical training-and

afterwards

Angela $R$ Cunningham, FRCR; Frances

Margaret Ulyatt, FFARCS; J M Cundy, FFARCS 54

The Oxford part-time scheme

J M Potter, FrCs. . . . . . . . . . . . . . . 54

Excessive working hours for junior doctors

A M Kaiser, $\mathrm{MB} \ldots \ldots \ldots \ldots \ldots \ldots \ldots \ldots 55$

Treating overseas visitors

A D Brittlebank.................... 55

Changes in DCH examination

D A Pyke, FrCP.............. 55

Embattled and impoverished

P V Scott, FFARCS................. 55

Olympic doctors

H J Ross, frCs ............... 55

We may return unduly long letters to the author for shortening so that we can offer readers as wide a selection as possible. We receive so many letters each week that we have to omit some of them. Letters must be signed personally by all their authors. We cannot acknowledge their receipt unless a stamped addressed envelope or an international reply coupon is enclosed.

Correspondents should present their references in the Vancouver style (see examples in these columns). In particular, the names and initials of all authors must be given unless there are more than six, when only the first three should be given, followed by et al; and the first and last page numbers of articles and chapters should be included. Titles of papers are not, however, included in the correspondence section.

\section{Is bran useful in diverticular disease?}

SIR,-Discussing your subject for debate "Is bran useful in diverticular disease ?" $(5$ December, p 1523), Dr K W Heaton writes, "A problem with all controlled trials of bran is that the use of a standardised dose ignores the pronounced variability in people's response to bran and prevents the investigator from treating each patient as an individual, which is how he is treated in clinical practice."

It is nearly 30 years $^{1}$ since I maintained that statistically there is no reason against a trial with a variable dose. One merely changes the question asked from (a) "What is the upshot if some fixed dose of a drug (or foodstuff) is given uniformly to all patients ?" to $(b)$ "What is the upshot if clinicians in charge of patients give such varying amounts as seem, in their judg ment, to be advisable?" In both cases the results in the group as a whole can be compared with those in a control group.

The only proviso, perhaps needful, is that one can certainly not subdivide the treated group to measure the effects of the different amounts, since those amounts have already been determined by the conditions and responses of the individual patients. That would be circular reasoning.

Austin BRADFord HiLl

Shrewsbury SY4 1DL

${ }^{1}$ Hill AB. N Engl f Med 1952;247:113.

SIR,-Increasingly it becomes apparent that well-conducted clinical trials fail to provide the

clinicians with clearcut answers which can be reproduced. The frustrations arising from the bluntness of this potentially most important research tool have been the subject of recent comment. ${ }^{1-3}$ This difficulty has been highlighted again by the recent contradictory papers on the treatment of diverticular disease with bran. In his analysis of this problem Dr $\mathrm{K}$ W Heaton (5 December, p 1523) draws attention to the need for different series to relate to patients with similar degree of clinical severity.

I believe that this is an important general point and that clinical trials should relate to patients where further therapeutic help is really needed and exclude those whose symptoms settle spontaneously with nonspecific care. It is these quick responders who can blur the difference between controls and

\section{Misplaced confidence in nebulised bronchodilators in severe asthmatic attacks}

SIR,-Dr A E Gale (14 November, p 1336) has described a hand-operated pump for nebulising a bronchodilator, which asthmatic patients can use if they have to travel long distances from home. Although his letter made no reference to death, the use of the running heading for this correspondence ("Deaths from asthma on holiday") might seem to imply that a nebulised bronchodilator is the most effective form of treatment in severe or life-threatening attacks. This is a misconception which it is essential to correct, particularly since an increasing number those receiving the treatment under study. This point was appreciated by Sir Richard Doll ${ }^{4}$ in his early classic studies on the factors influencing the rate of healing of gastric ulcer. He excluded the rapid healers by a second $x$-ray examination two weeks after the first one; and the remainder, where further help was really needed, were admitted into his series. The failure of so many later trials to follow this example I believe explains the difficulty of interpreting the significance of many peptic ulcer studies.

F AVERY JONES

London W2 6DA

1 Sherry S. Eur 7 Clin Pharmacol 1980;17:79-80.

2 Ritter JM. Lancet 1980;i:1126-27.

Sancho, H, Hayat M. Biomedicine 1973;18:173-6. .

of general practitioners are considering the purchase of a compressor.

There is no doubt about the value of nebulised bronchodilators for treating mild attacks in young children ${ }^{12}$ since the only form of bronchodilator which they may have taken already is tablets or syrup. Older children and adults, on the other hand, will almost invariably have taken a bronchodilator aerosol: provided that this has been taken correctly, it is difficult to understand why nebulising the same or another bronchodilator should be much more 
effective in relieving airflow obstruction which has shown itself to be refractory. While some improvement may be due to rehydration of the bronchi, much of the relief claimed by patients is often subjective; if this is mistaken for a true reduction of airflow obstruction, a potentially dangerous situation may exist.

Measurement of peak expiratory flow (PEF) before and after nebulisation is therefore mandatory. Although some rise of PEF may occur, what is of crucial importance is the magnitude of airflow obstruction which remains after nebulisation. In one study ${ }^{3}$ of nebulised salbutamol in mild or moderate attacks in children aged 5-13 years (range of predicted PEF 130-350 1/min) PEF improved by only $30-145$ (mean 55 ) $1 / \mathrm{min}$. In another study, ${ }^{4}$ of nebulised salbutamol in adults with acute severe asthma, subjective relief was reported by almost all patients; yet the mean improvement of PEF was $51 \mathrm{l} / \mathrm{min}$ and the highest PEF after nebulisation was only 248 $1 / \mathrm{min}$.

A large degree of airflow obstruction persisting after a nebulised bronchodilator has been used indicates the probable presence of mucosal oedema and exudation; in a longstanding attack this may have progressed to plugging. This inflammatory component can be reversed only by a corticosteroid. A recent inquiry into deaths from asthma ${ }^{5}$ concluded that a failure to consider any treatment other than a bronchodilator and incorrect assessment of severity were frequent contributory factors. In another retrospective study, ${ }^{6}$ of patients who had died outside hospital, it emerged that almost half of them had not been given a corticosteroid. The following two case histories illustrate the danger of subjective impressions of improvement after nebulisation.

Case 1-A man aged 43 years first began to have asthma in November 1980. After a short course of prednisone his PEF rose to $5401 / \mathrm{min}(87 \%$ of predicted normal). He remained free of symptoms until September 1981, when after a respiratory infection he became severely breathless. Inhalation of salbutamol aerosol gave only slight relief. He was given nebulised salbutamol with great subjective relief, his PEF rising from 165 to $2601 / \mathrm{min}$. The improvement was short lived and over the next two days his asthma became steadily more severe. He became unable to speak and his wife feared that he might die, but he refused to call for an emergency visit. Next morning he was driven to the medical centre, where he was given corticotrophin ( 80 units) and a four-day course of prednisone $(40 \mathrm{mg}$ daily). Two days later his PEF had risen to $4501 / \mathrm{min}$, and by the sixth day airflow obstruction had been completely abolished (PEF $5501 / \mathrm{min}$ ).

Case 2-A girl aged 6 years had had recurrent attacks of severe asthma and had been admitted to hospital on three occasions in the previous year. During an attack in August 1981 her PEF was $130 \mathrm{l} / \mathrm{min}$ ( $39 \%$ of predicted), but after a short course of prednisone it rose to $335 \mathrm{l} / \mathrm{min}$. Thereafter her asthma was reasonably controlled, twice daily measurements of PEF being in the range of $200-3001 / \mathrm{min}$. In November a respiratory infection provoked severe asthma and she was brought for treatment. Nebulisation of salbutamol gave considerable subjective improvement, but this was only temporary and during the following night she became severely dyspnoeic. Next day there was marked hyperinflation, with use of accessory muscles and tachypnoea (PEF $851 / \mathrm{min}$ ). She was given corticotrophin (40 units), followed by a fourday course of prednisone ( $20 \mathrm{mg}$ daily); within 48 hours her PEF had risen to $260 \mathrm{l} / \mathrm{min}$, and seven days later it was $3601 / \mathrm{min}$ ( $109 \%$ of predicted).

In their letter about deaths from asthma on holiday Dr I W B Grant and Dr G K Crompton (16 May, p 1621) comment that four patients might have survived if they had been able to obtain expert hospital care, such as that provided by their own emergency admission service in Edinburgh. ${ }^{7}$ However, preoccupation with the treatment of severe attacks must not be allowed to direct attention away from the measures necessary to prevent them. The four patients might have survived if they had understood that the failure of a bronchodilator aerosol to give relief is an indication of a potentially serious situation and they should have known what measures to take on their own initiative. If a general practitioner instructs his patients to take a short "preemptive" course of a corticosteroid in these circumstances, admissions to hospital can be greatly reduced. ${ }^{8}$ On the other hand, the much wider use of nebulised bronchodilators by general practitioners would be unlikely to reduce admissions, except in young children. ${ }^{2}$ It is even conceivable that errors of assessment might lead to an increase in deaths.

Cardiothoracic Institute,

Kingston-upon-Thames,

Surrey KT16 $6 \mathrm{HR}$

1 Lenney W. Lancet 1978; ; :440-1.

Howarth NJ, Gadsby R. Lancet 1980;ii:1202.

Bannister OM. Physiotherapy 1980;66:144. wford P, Jones BJM, Milledge JS. Br Med $\mathcal{F} 1978$ i:84.

Lancet $1981 ; \mathrm{ii}: 747$. Macdonald JB, S

$1976 ; i: 1493-5$

Crompton GK, Grant IWB, Bloomfield P. Br Med $\mathcal{f}$ 1979; ;i:1199-201.

${ }^{8}$ Gregg I. Br Med f 1968;ii:175-6.

\section{Bronchial hyperreactivity after} inhalation of distilled water and saline

SIR,-In their article on bronchial reactivity to distilled water and saline (14 November, p 1285) Robin E Schoeffel and others found no significant fall in forced expiratory volume in one second in their asthmatic patients after inhalation of isotonic $(0.9 \%)$ saline. We think that this could be misleading since we find that about one in three asthmatic patients develop dose-dependent bronchoconstriction after inhaling isotonic saline from an air-driven nebuliser at room temperature. This reaction is abolished when inhalation is carried out at $37^{\circ} \mathrm{C}$ and $100 \%$ relative humidity, ${ }^{\prime}$ which indicates that the bronchoconstriction is due to a cooling effect of the inhalation by a mechanism analogous to that underlying exercise-induced asthma. In fact, two of their 10 asthmatic patients appear to fit into this category, since they showed a fall of more than $20 \%$ from baseline after inhaling isotonic saline. Thus normal saline should not be considered inert and is not a suitable control for bronchial challenge studies.

The changes seen after isotonic saline appear to be due to airway cooling and we doubt whether temperature changes between $22^{\circ} \mathrm{C}$ and $35^{\circ} \mathrm{C}$ would be unimportant, as the authors suggest, if they were looked at critically in conjunction with studies of relative humidity. Further work is needed to see if the effects of hypotonic and hypertonic solutions are affected by temperature and humidity.

RICHARD LEWIS ANNE E TATTERSFIELD University of Southampton Faculty of Medicine, Southampton General Hospital,

${ }^{1}$ Lewis RA, Tattersfield AE. Clin Sci 1980;59:12p.
The secret technical defence: a case for changing the law

SIR,-Professor Alan Usher complains (5 December, $p$ 1542) that he was confronted with "secret histological evidence" by the defence and had inadequate time to study it during the trial of Dr Leonard Arthur. From this experience he suggests that the law should be changed.

In truth Home Office pathologists have many advantages over the pathologist appearing for the defence. Since they are the first to carry out a postmortem examination they are able to study the appearances in a pristine state. They have the assistance of a highly trained scenes of crime police team. The Home Office forensic laboratories with their vast expertise are available to them for analyses and, in Professor Usher's case, he has the backing of a well-staffed, university-funded histopathology laboratory. Finally, if he is uncertain of his interpretation of the findings he is free to seek whatever specialised advice he may desire before reaching his final conclusions about the cause and manner of death.

The pathologist instructed by the defence is commonly in a very different position. Several weeks may have passed before he is instructed and the postmortem appearances will have markedly changed as a result of this and of the first necropsy. He must work alone without the support of the police team or the Home Office laboratories, which are not open to defendants. But these disadvantages present a challenge to him and so he will research the literature, think more deeply, and carry out investigations which, albeit with hindsight, the Home Office pathologist is often shown to have failed to pursue. As a result he may offer the court alternative explanations for the death.

We know of instances where deaths alleged to be due to homicidal shooting, drowning, asphyxia, and head injury have been demonstrated to have a very different explanation, or at least more than one possible explanation, as a result of investigations carried out by the defence pathologist. Before these investigations could be completed, usually before they could start, the accused has been charged. The only way in which a defendant can be given a fair trial is to present the evidence to the judge and jury, who have the task of deciding whether the alleged cause of death which incriminates the accused is proved beyond a reasonable doubt.

It is naive of Professor Usher to suggest that to save the Home Office pathologist from embarrassment he should be apprised of new evidence elicited by the defence after the police inquiry has been concluded. If he has completed his investigations skilfully and conscientiously he should be able to defend his conclusions successfully under crossexamination. If there is any doubt in his mind it is open to him to obtain a second opinion before presenting his case to the prosecutor.

We also take exception to the implication that the lawyer is not concerned to arrive at the truth. Professor Usher is, of course, right in saying that defence counsel's job is to present the best possible case for his client; but our trial procedure (which has proved itself to be the envy of the world) is based on an adversarial system which, so far from condoning "secret defences," has safeguards built in to prevent the truth being concealed. The law is that if the prosecution are presented by the defence with any evidence which they could 